\title{
KULTURA STRACHU
}

\author{
STANISŁAW PUPPEL, JOANNA PUPPEL
}

„Strach jest oparty na obawie kary; Ten więc nie zawiedzie nigdy"

(Niccolo Machiavelli, Książe)

\begin{abstract}
The 'culture of fear' constitutes an important environment for mankind. It is an interplay of biological, socio-cultural and linguistic dimensions which, in fact, underlie human existence. The dominance of one subtype of culture with respect to fear, the dystopian culture, pulls mankind into a culture of aggression, competitiveness and intolerance (or into the win-lose perspective). On the other hand, eutopian culture pulls mankind into a culture of non-aggression, cooperation, tolerance and inclusiveness (or into the win-win perspective). In fact, one may easily envisage that a well-functioning human society should remain in a state of balance between the two types of culture and it is the dystopian type of culture that should be kept in check, while the eutopian culture should be favoured if the earth as the carrier of all life, the existing biodiversity, and humanity, are to be sustained.
\end{abstract}

Key words: fear, biology of fear, fear learning, fear permanence, culture of fear, dystopian culture, eutopian culture, binding culture, binding language

\section{Wstęp}

'Kultura strachu' to pojęcie, które dotyczy tworzenia, odczuwania i uprawiania strachu w wymiarze językowo-kulturowym, a więc w wymiarze pozabiologicznym człowieka. Wszakże założyć jednocześnie należy, że jest to pojęcie bezpośrednio związane ze zjawiskiem strachu istniejącym w wymiarze czysto biologicznym i z niego się wywodzącym. Strach biologiczny (tj. strach wrodzony) charakteryzuje (zapewne wszystkie) istoty żyjące na nośniku ziemskim, z jednej bowiem strony istoty żywe 
obdarzone są silnym pragnieniem istnienia za wszelką cenę (jak byśmy powiedzieli za Grekami, wszystkie posiadają 'zooepitymię', czyli pożądanie życia) i uczą się odpowiednio reagować na wszelkie środowiskowe bodźce, które przewidują także potencjalnie szkodliwe zjawiska i efekty. $Z$ drugiej zaś strony obdarzone są równie silnym pragnieniem poszukiwania i dostarczenia sobie skutecznej ochrony przed niebezpieczeństwami (zagrożeniami) pochodzącymi głównie ze świata zewnętrznego. Ta właśnie nierozerwalna dychotomia 'życia' i 'ochrony życia' stanowi podstawę' pojetyki' wszelkiego życia, w tym pojetyki życia człowieka, programowo, a więc genetycznie, dodatkowo nasyconego strachem, jako jednego z gatunków biologicznych strachowi podlegającego. Jak złożonym zjawiskiem jest zjawisko strachu i niepokoju w czysto biologicznym wymiarze ukazuje ważna przeglądowa praca Thierry'ego Steinera (2002), rzucająca światło na całą gamę uwarunkowań biologicznych istnienia strachu zarówno u zwierząt jak i u człowieka.

W tak szerokim, biologiczno-kulturowym, ujęciu 'kultura strachu' stanowi część pojetyki życia człowieka jako odrębnego gatunku w kontekście całej stworzonej przez niego' otuliny kulturowej' (zob. np. Maturana i Varela, 1980). Zatem 'kultura strachu' jest postrzegana tutaj tylko jako wydzielona część całokształtu kultury, jako specyficznie ludzka strona pojetyki wszelkiego życia na nośniku ziemskim (zob. np. Tuan, 1979).

Ze względu na swoje centralne znaczenie dla życia człowieka musi zarówno ona jak i jej 'anatomia' zostać w pełni opisana, bowiem w sposób naturalny należy jako zagadnienie do szeroko pojętych badań w zakresie antropologii, kulturoznawstwa, językoznawstwa i komunikologii. Stąd niniejsza krótka próba przedstawienia zagadnienia strachu i towarzyszącej mu przemocy w właśnie perspektywie antropologiczno-kulturowo-komunikacyjnej (zob. np. Hallpike, 1979; Boscoboinik i Horakova, 2014).

\section{Biologia strachu}

Czysto ludzkie odczuwanie strachu jako jednej z podstawowych emocji ma swoją podstawę $\mathrm{w}$ strukturze i bogatych połączeniach strukturalnych umiejscowionych w centralnym układzie nerwowym, jakim jest mózg człowieka (zob. np. LeDoux, 1998; LeDoux, 2000; LeDoux, 2012; Adolphs, 2013). W szczególności jest za niego odpowiedzialny tzw. system limbiczny (łac. Systema limbicum, ang. limbic system, po raz pierwszy postulowany w XIX wieku przez neurofizjologa i antropologa francuskiego, Paula Broca (1824-1880), wykorzystany szeroko w XX wieku przez neurofizjologa i psychiatrę amerykańskiego, Paula MacLean'a (1913-2007)), umieszczony w przedniej części płata skroniowego (ang. temporal lobe). Składają się na niego następujące części: płat limbiczny (ang. limbic lobe), kora okołoczodołowa (ang. orbitofrontal cortex), kora gruszkowata (ang. piriform cortex), kora śródwęchowa (jelitalna, ang. entorhinal cortex), hipokamp (ang. hippocampus), sklepienie 
(ang. fornix), jądra przegrody (ang. septal nuclei), ciało migdałowate (ang. amygdala), jądro półleżące (ang. nucleus accumbens), a także wzgórze (ang. thalamus). To ostatnie uważane jest przez neurofizjologów za swoistą 'bramę do świadomości' (ang. gateway to consciousness), która jest także swoistym siedliskiem strachu i wstrętu (zob. np. Isaacson, 1982; Calder i inni, 2001; Scholpp, Whalen i Phelps, 2009; S. i T. Shimogori, 2013).

System ten, jak widać ogromnie złożony i wykształcony w długotrwałym procesie ewolucyjnym, musi mieć dla człowieka pierwszorzędne znaczenie. Odpowiada bowiem nie tylko za utrzymywanie emocji w pamięci długoterminowej ale także za ich generowanie $w$ różnych środowiskowo zdeterminowanych wariantach i nasileniach (w sensie 'endo' i 'egzo') przez poszczególnych ludzi. Musi mieć więc znaczenie przetrwalnikowe dla gatunku człowieka

$\mathrm{W}$ opracowaniach z zakresu funkcjonowania systemu limbicznego (zwanego także przez MacLean'a 'mózgiem paleossaczym', ang. paleomammalian brain, old mammalian brain, zob. Maclean, 1990) podkreśla się, że, współpracując silnie $\mathrm{z}$ nowokorą (ang. cerebral cortex, neocortex, neomammalian brain), a więc ewolucyjnym uwieńczeniem struktur mózgowych u człowieka jako gatunku, jest odpowiedzialny za cały kompleks zjawisk jak chociażby: powonienie, wszelkie emocje, popędy, symptomy psychoz, fobie, postrzeganie czasu, zachowania motoryczne i ogólnie przetwarzanie sensoryczne jak i świadomość.

Jest więc w pełni zrozumiałe, że zarówno konkretne emocje jak i pamięć długoterminowa mają istotne znaczenie dla przeżywalności człowieka, w szczególności znaczenie takie ma obecność nie tylko strachu wrodzonego, będącego odpowiedzią na agresję występującą w naturze (tzw. 'agresję reaktywną' (ang. reactive aggression), zob. Wrangham, 2019; zob. także Lorenz, 1974), ale także strachu nabytego i uczenia się tegoż (ang. fear learning, zob. np. Olsson i inni, 2007; Olsson i Phelps, 2007) w życiu człowieka jako odrębnego gatunku jak i poszczególnych ludzi. Stąd strach ma tak wielkie znaczenie dla kultury jako otuliny człowieka, którą człowiek wygenerował w swojej gatunkowej ewolucji i w której przebywa przez całe swoje osobnicze życie, obok czysto biologicznego wymiaru strachu obejmującego funkcjonowanie systemu limbicznego i połączonej z nim nowokory, na zasadzie światów równoległych.

Można powiedzieć, że właśnie ze względu na wykształconą w toku ewolucji pamięć długoterminową gatunek ludzki posiadł strach i jego czysto fizjologiczne odczuwanie na zasadzie jego permanencji (zjawisko długotrwałości strachu), być może zabezpieczanej genetycznie (o czym wspomina np. genetyka psychiatryczna, zob. np. Kendler i inni, 2008; także Bourke, 2005) i przez cały czas swojego istnienia poddany jest działaniu strachu, mającego swoje odbicie w takich konstrukcjach werbalnych w języku polskim jak: 'sianie strachu', 'ktoś podszyty jest strachem' i 'ktoś żyje strachem' (w wersji łagodniejszej 'ktoś podszyty niepokojem' i 'ktoś sieje niepokój i zamęt', 'strach bierze, gdy pomyślę'), tak jak żyje innymi emocjami, takimi 
chociażby jak: rozkoszą, pożądaniem, szczęściem, radością, gniewem, smutkiem, odrazą, zdziwieniem, wstydem czy dumą. Ale ze wszystkich tych emocji strach jest najbardziej podstawowy, najbardziej pierwotny, najbardziej dojmujący, najbardziej przenikliwy, najbardziej paraliżujący, najbardziej wszechobejmujący i najbardziej ze wszystkich odrażający, wyprowadzony ze stanu zwierzęcego (zob. np. Sluckin, 1979; Bekoff, 2008).Wiemy też wszyscy, że strach potrafi zdewastować życie jednostki ludzkiej i każdej społeczności i że jest także czynnikiem generującym chaos. Nic zatem dziwnego, że ma on ogromną wartość kulturową, w tym także polityczną i że zajmuje w kulturze centralne miejsce.

\section{Podstawowa dychotomia kultury w perspektywie kultury strachu}

Kultura strachu, solidnie oparta na biologii człowieka i wrodzoności strachu, jak i na wczesnym uczeniu się strachu w życiu każdego człowieka, jest nie tylko integralną częścią kultury człowieka, ale jest podstawą określonej odmiany kultury człowieka, tj. 'kultury dystopijnej', którą możemy zdefiniować jako kulturę zła (obejmującą wszelkiego typu kolizje z innymi bytami biologicznymi skutkujące ich uszkodzeniem a nawet anihilacją), kulturę generowania i utrzymywania dominacji emocji negatywnych, promowania zaburzeń wszelakich i ogólnej dyspozycji do unikania wszelkich realizacji o charakterze pozytywnym, czyli niekolizyjnych i wiążących ludzi.

Kultura, o której mowa, jest przeciwieństwem 'kultury eutopijnej', a więc kultury dobra, z natury bezkolizyjnej, otwartej i opartej na empatii, a także charakteryzującej się ogólną dyspozycją do generowania i utrzymywania emocji pozytywnych oraz angażowania się jednostki ludzkiej w emocjonalnie pozytywnych interakcjach międzyosobowych. Może nawet obejmować interakcje o znacznie większej skali, bo obejmujące różne grupy zawodowe, etniczności, kultury lokalne i nawet państwa, a także twory wielopaństwowe (zob. np. Peale, 1990). Tak więc już na poziomie emocji ujawnia się podstawowa dychotomia kultury, czyli podział na kulturę dystopijną i kulturę eutopijną.

\subsection{Strach jako część kultury dystopijnej: układ polityczny, strach polityczny}

Strach w kulturze dystopijnej jest zjawiskiem, które nie tylko determinuje tę kulturę ale nabiera dodatkowo charakteru wyraźnie politycznego, które to zjawisko każdy człowiek zna i którego nieustannie doświadcza, przebywając przez całe swoje życie w sposób nieunikniony w obrębie takiego czy innego, mniejszego lub więk- 
szego (w skalach mikro i makro), 'układu politycznego', a więc układu opartego na relacjach (odniesieniach i powiązaniach) siłowych (przemocowych), takiego jak rodzina, wspólnota etniczna, partia, państwo, instytucja, wspólnota zawodowa, wspólnota zainteresowań, etc., a więc układu obejmującego wyraźnie złożone hierarchiczne zależności (zob. np. Robin, 2004).

Strach na płaszczyźnie politycznej dotyczy więc odczuwania przede wszystkim negatywnej presji w postaci różnorakich zagrożeń ze strony tegoż układu politycznego, w tym ze strony różnych jednostek ludzkich układ ten tworzących. Można powiedzieć, że 'strach polityczny' ma charakter zarówno zestrojony jak i wielopoziomowy, bowiem może być generowany nie tylko w ramach pojedynczego wymiaru układu politycznego, np. w mikro wymiarze rodziny, ale także może być wynikiem wspólnego działania (synergii) wszystkich elementów danego układu politycznego jednocześnie. Taki właśnie zestrojony, a więc wielowymiarowy, wymiar strachu politycznego ma, ze względu na swój ciężar, największą 'siłę rażenia' (ang. the power of impact) i największą 'żywotność' (ang. vitality). Nic zatem dziwnego, że w politycznym trwaniu każdego człowieka i stworzonych przezeń w perspektywie historycznej większych układów politycznych (np. imperiów i państw), ów zestrojony i wielowymiarowy strach polityczny miał i nadal ma największe znaczenie. Nic też zatem dziwnego, że największe skupiał na sobie zainteresowanie ze strony filozofów i badaczy od czasów starożytnych aż po dzień dzisiejszy (zob. np. Machiavelli i jego nieśmiertelny Książę, także dane bibliograficzne podane poniżej).

\subsubsection{Uprawianie strachu w kulturze dystopijnej}

Proponując termin 'uprawianie strachu'(ang. cultivation of fear) opieramy się na pierwotnym znaczeniu słowa 'kultura' (łac. cultura) oznaczającym w języku łacińskim 'uprawę, pielęgnację'. Uważamy, że 'kulturę strachu' w wymiarze politycznym uprawia człowiek od niepamiętnych czasów właśnie na modłę uprawy gleby, czyli tak, aby przynosiła ona jak najwyższe plony temu, który ją uprawia z jednoczesną szkodą dla innych uczestników-biorców tej kultury. Można sobie łatwo wyobrazić, że szeroka paleta uprawiania kultury strachu w żywej i nieustannie zmieniającej się tkance naszej cywilizacji, systematycznie udoskonalana przez ludzkość od biblijnego Raju poprzez różne konstrukcje polityczne imperialno-totalitarno-autorytarne, w dzisiejszych czasach potworność Archipelagu Gułag i Auschwitz-Birkenau, do czasów całkowicie nam współczesnych, obejmuje ogromną liczbę wariantów. Poniżej przedstawiamy je w formie skrótowej i tym samym dalekiej od wyczerpania, dodatkowo ograniczonej pojemnością niniejszego eseju, niemniej dające wyrazisty obraz złożonej tekstury jej 'wiecznego życia'. Oto one:

- wrodzony strach przed utratą życia, głodem, chorobami, kalectwem i samotnością,

- wrodzony strach przed światem zewnętrznym i przed nieznanym (tj. naturalnym nośnikiem ziemskim i zjawiskami na nim występującymi (np. atmosfe- 
rycznymi, geologicznymi, epidemiami, ciemnościami, głębinami, etc.), a także żyjącymi na niej istotami niebędącymi ludźmi),

- strach przed innym człowiekiem, zwłaszcza takim, o którym wiemy, że świadomie należy do kategorii ‘komunikatorów przemocy', zwłaszcza w pełni zaplanowanej tzw. 'przemocy proaktywnej' (ang. proactive aggression, zob. Wrangham, 2019), tj. uprawiających wszelką przemoc fizyczną i/lub przemoc militarno-technologiczno-językowo-komunikacyjną w celu ustanowienia dominacji poprzez instytucjonalizację przemocy (zob. np. w tym kontekście postać imperatora budującego swoje imperium poprzez najazdy zewnętrzne i represje, włącznie z formami ludobójstwa, stosowane we własnym kraju, zob. np. Diamond, 1974, czy postać w pełni uzbrojonego średniowiecznego rycerza jako bezwzględnego narzędzia wszelkich terytorialnych najazdów oraz jako swoistego komunikatora przemocy, zarówno fizycznej jak i werbalno-gesturalnej), strach przed bezwzględnym autokratą i jego aparatem przemocy w ramach państwa represyjnego, czy też strach kobiety przed dopuszczającym się gwałtów cywilnym mężczyzną (zob. np.Shahar, 1983; McNellis, 2008), czy też uzbrojonym po zęby żołnierzem stosującym gwałt na kobietach jako swoistą broń masowego rażenia (zob. np. Brownmiller, 1975; Card, 1996), także strach przed agresywnym tłumem (zob. np. Fromm, 1973),

- strach przed niektórymi 'twardymi' wytworami człowieka (ang. tangible artecrafts), np. budynkami i konstrukcjami (ołtarze ofiarnicze, areny gladiatorskie, więzienia, koszary, szpitale, izby tortur, rzeźnie, krematoria, szubienice, gilotyny, etc.), narzędziami, technologiami, maszynami i bronią (zob. np. Berdan, 1982; Smith i Masson, 2000; Źrałka, 2008; Olko, 2010),

- strach przed 'miękkimi' wytworami człowieka (ang. intangible artecrafts) i ich skutkami, np. sztucznie wytworzonymi środkami chemicznymi i biologicznymi (np. gazami bojowymi, truciznami), naturalnymi epidemiami wytworzonymi wskutek braku higieny, różnymi strukturami i systemami społecznymi, ideologiami, religiami, rytuałami, ekonomiami preferującymi 'przemoc proaktywną’ czy wręcz na niej opartymi (ang. proactive coercion) indywidualną i zbiorową, etc. (zob. np. Robin, 2004; Molenda, 2013),

- zbiorowy i indywidualny strach przed utratą niezagrażającego życiu środowiska naturalnego wskutek długotrwałych negatywnych oddziaływań człowieka (zob. np. Lovelock, 2007, czy pojęcie 'antropopresji negatywnej' w ekologii, zob. np. Brown et al., 2013).

\subsubsection{Sposóby na osłabienie kultury strachu}

Kulturze strachu, która - gdy będzie pozostawiona samej sobie w pozycji hegemona - mogłaby w dłuższej pespektywie czasowej po prostu skolonizować kulturę człowieka, tj. bez reszty opanować całokształt życia ludzkiego, przeciwstawić moż- 
na i należy kulturę z jednej strony opartą na jej strukturalnym braku, z drugiej zaś opartą na pragnieniu jej całkowitego usunięcia czy też przynajmniej zminimalizowania jej skali i zasięgu, gdyż prawo do wolności od strachu (ang. freedom from fear) stanowi jedno z podstawowych praw człowieka i zarazem niezbywalny składnik 'ludzkiego dobrostanu' (ang. human wellbeing).

Kulturą tą, obdarzoną potencjałem przeciwstawienia się kulturze strachu, jest wymieniona powyżej 'kultura eutopijna' (kultura empatyczna), a więc szeroko pojęta 'kultura więzi' (ang. binding culture) i szczęścia (zob. np. Platon i jego nieśmiertelne Państwo; Plato, 1997). Jest ona oparta głównie na redukcji przemocy proaktywnej oraz uznawaniu zarówno istoty pojedynczego człowieka, jego nieusuwalnej i nieredukowalnej pełni jak i na zasadzie utrzymywania bezkolizyjności wszelkich relacji pomiędzy poszczególnymi jednostkami ludzkimi, a także pomiędzy znacznie większymi tworami społecznymi (różnymi grupami społeczno-zawodowymi, etnicznościami, narodowościami, państwami, zbiorowościami regionalnymi i ponadregionalnymi, etc.)

W wyłaniającej się coraz wyraźniej kulturze typu eutopijnego zasoby językowokomunikacyjne odegrają (już zaczynają odgrywać) zasadniczą rolę w komunikacji typu eutopijnego. Polegać ona będzie najogólniej na:

- coraz szerszym i coraz bardziej świadomym stosowaniu tzw. 'języka łączenia' (ang. binding language) jako podstawowego elementu kultury więzi, a nie tylko 'języka podziałów' (ang. divisive language),

- konsekwentnym usuwaniu wszelkich przejawów przemocy, zarówno twardej jak i miękkiej, np. poprzez różne formy tworzenia opozycji wobec wszelkich mniej lub bardziej tyrańskich zabiegów na płaszczyźnie politycznej,

- wyrażaniu współczucia i tolerancji za pomocą odpowiednich środków językowo-komunikacyjnych (retoryka włączania, ang. the rhetoric of inclusion),

- udziale we wszystkich możliwych wspólnotach na zasadzie pełnego uczestnictwa (tj. pełnego i pozytywnego zaangażowania poszczególnych jednostek i całkowitej afirmacji ich działań),

- także pilnym i starannym zapobieganiu dewastacji języka na poziomie wysokiego nasycenia emocjami negatywnymi i używanego w komunikacji codziennej (zob. Dixon, 2012; Puppel, 2019).

Powstaje w tym momencie podstawowe pytanie: Czy 'kultura strachu' pozostanie stałym i nieusuwalnym elementem cywilizacji człowieka w XXI wieku? Pytanie to pozostaje zagadnieniem otwartym i niezwykle aktualnym, ale już dzisiaj możemy przyjąć, nawet w skrajnych warunkach obecności różnych czynników wzbudzających powszechny strach, np. mocno osłabionej kondycji ziemi jako nośnika wszelkiego życia wskutek rosnącej antropopresji, obecności globalnej pandemii koronawirusa $\mathrm{i}$ innych groźnych pandemii w przyszłości, czy globalnego ocieplenia niosącego m.in. zagrożenie zalania wielu centrów cywilizacyjnych ludzkości, że całkowite usunięcie 'kultury strachu’ lub chociażby zauważalne społecznie jej osłabienie (vis-a-vis czysto 
biologicznych przesłanek strachu pokrótce omówionych powyżej), miałoby niezwykle pozytywny wpływ na dalsze istnienie i rozwój ludzkości w kontekście wymienionych powyżej zagrożeń. Stąd też szczególnego znaczenia nabierają wspomniane powyżej zasoby językowo-komunikacyjne języka łączenia, które przy odpowiednim stanie świadomości komunikatorów będą w stanie sprostać zadaniu thumienia (a może i wyłączania z użycia) zasobów językowo-komunikacyjnych o charakterze dystopijnym.

Zapewne $\mathrm{z}$ czysto pragmatycznego punktu widzenia w dalszym toku istnieniu rodzaju ludzkiego będziemy mieli do czynienia $\mathrm{z}$ istnieniem i wykorzystywaniem pewnego rodzaju równowagi pomiędzy kulturą dystopijną a kulturą o charakterze eutopijnym, z rosnącą wszakże tendencją do poddania tej pierwszej szczególnej społecznej kontroli. Docelowo zatem kultura eutopijna winna z czasem uzyskać bardziej dominującą pozycję w całokształcie ludzkich wysiłków o charakterze ekologicznym, z natury swojej o charakterze empatycznym, a więc na rzecz globalnych celów ratowania nośnika ziemskiego, naturalnej różnorodności i dalszego zabezpieczania istnienia ludzkości z wszystkimi jej determinantami, co powinno w dłuższej perspektywie czasowej sprzyjać także rozwojowi i utrzymywaniu zasobów językowokomunikacyjnych o charakterze eutopijnym.

\section{Bibliografia}

Adolphs, R. 2013. ”The biology of fear". Current Biology 23.2. R79-R93.

Al-Shawaf, L., D. Conroy-Beam, K. Asao and D.M. Buss. 2015. "Human emotions: an evolutionary psychological perspective". Emotion Review. 1-14.

Bekoff, M. 2008. The emotional lives of animals: a leading scientist explores animal joy, sorrow, and empathy - and why they matter. Novato, CA: New World Library.

Berdan, F.F. 1982. The Aztecs of Central Mexico: am imperial society. New York: Holt, Rinehart and Winston.

Boucheron, P. 2020. Machiavelli: the art of teaching people what to fear. New York: Other Press.

Bourke, J. 2005. Fear: a cultural history. London: Virago Press.

Brown, C.J., M.I. Saunders, H.P. Possingham i A.J. Richardson. 2013. "Managing for interactions between local and global stressors of ecosystems". PLos ONE 8.6 e657.

Brownmiller, S. 1975. Against our will: men, women and rape. New York: Bantham Books.

Boscoboinik, A. i H. Horakova. (red.). 2014. The anthropology of fear: cultures beyond emotions. Freiburg Studies in Social Anthropology. Münster: LIT Verlag.

Calder, A.J., A.D. Lawrence i A.W. Young. 2001. "Neuropsychology of fear and loathing". Nature Reviews Neuroscience 2. 352-363.

Card, C. 1996. "Rape as a weapon of war". Hypatia 11.4. 5-18.

Darwin, C. 1872/1998. The expression of the emotions in man and animals. Oxford: Oxford University Press.

Diamond, S. 1974/1987. In search of the primitive: a critique of civilization. New Brunswick, N.J.: Transaction Books.

Dixon, R. 2012. How to overcome fear, and start living fearless. CreateSpace Independent Publishing Platform.

Fromm, E. 1973. The anatomy of human destructiveness. New York: Henry Holt. 
Gardner, D. 2008. Risk: the science and politics of fear. New York: Random House.

Hallowell, A.I. 1938. "Fear and anxiety as cultural and individual variables in a primitive society". Journal of Social Psychology 9. 25-47.

Hallpike, C.R. 1979. The foundations of primitive thought. Bungay, UK: Richard Clay.

Hankiss, E. 2001. Fears and symbols: understanding the role of fear in Western civilization. Budapest: Central European University Press.

Isaacson, R.L. 1982. The limbic system. $2^{\text {nd }}$ ed. New York: Plenum Press.

Kendler, K.S., C.O. Gardner, P. Annas, M.C. Neale, L.J. Eaves i P. Lichtenstein. 2008. "A longitudinal twin study of fears from middle childhood to early adulthood: evidence for a developmentally dynamic genome". Archives of General Psychiatry 65.4. 421-429.

Krishnamurti, J. 1994. On fear. New York: HarperCollins.

LeDoux, J.E. 1998. The emotional brain: the mysterious underpinnings of emotional life. New York: Simon and Schuster.

LeDoux, J.E. 2000. "Emotion circuits in the brain". Annual Review of Neuroscience 23. 155-184.

LeDoux, J.E. 2012. "Evolution of human emotion: a view through fear". Progress in Brain Research 195. 431-442.

Lester, D. 1975. "The fear of death in primitive societies". Behavior Science Research 10.3. 229-232.

Linke, U. i D.T. Smith. (red.). 2009. Cultures of fear: a critical reader. London: Pluto Press.

Lorenz, K. 1974. On aggression (Tłumaczenie oryginału niemieckiego pt. Das sogennante Böse. Zur Naturgeschichte der Aggression z roku 1963). Boston: Mariner Books.

Lovelock, J. 2007. The revenge of Gaia: Earth's climate crisis and the fate of humanity. New York: Basic Books.

Machiavelli, N. 1532/2005. Ksiązę (tłumaczenie Il principe na język polski: Anna Klimkiewicz). Kraków: Zielona Sowa.

MacLean, P.D. 1990. The triune brain in evolution: role in paleocerebral functions. New York: Plenum Press.

Maturana, H.R. i F.J. Varela. 1980. Autopoiesis and cognition: the realization of the living. Boston: Reidel.

McNellis,L. 2008. 'Let her be taken': sexual violence in medieval England. Orlando, FL: University of Central Florida (An unpublished thesis submitted in partial fulfillment of the degree of Master of Arts in history).

Molenda, J. 2013. Ofiary z ludzi. Od faraonów do wikingów. Warszawa: Bellona.

Olko, J. 2010. Meksyk przed konkwista. Warszawa: Państwowy Instytut Wydawniczy.

Olsson, A., K.I. Nearing and E.A. Phelps. 2007. "Learning fears by observing others: the neural systems of social fear transmission". SCAN2. 3-11.

Olsson, A. i E.A. Phelps. 2007. "Social learning of fear". Nature Neuroscience 10.9. 1095-1102.

Peale, N.V. 1990. The power of positive thinking. New Delhi: Cedar Books. (Also 2003 New York: Touchstone).

Plamper, J. 2012. The history of emotions: an introduction. Oxford: Oxford University Press.

Plamper, J. i B. Lazier. (red.). 2012. Fear: across the disciplines. Pittsburgh: University of Pittsburgh Press.

Plato. 1997. Complete works. (Redakcja: J.H. Cooper). Indianapolis: Hackett.

Puppel, S. 2019. "Bagno językowo-komunikacyjne: uwagi w sprawie mechanizmów odwracania/zniekształcania znaczeń, osłabiania znaczeń i opróżniania pojęć, czyli o pokusie tworzenia pustostanów semantycznych". Electronic Journal Oikeios Logos nr 14. 1-7.

Robin, C. 2004. Fear: the history of a political idea. Oxford: Oxford University Press.

Shahar, S.1983/2003. The fourth estate: a history of women in the Middle Ages. London: Routledge.

Scholpp, S. I T, Shimoghori. 2013. "Building the gateway to consciousness - about the development of the thalamus". Frontiers in Neuroscience doi:10.3389/fnins.2013.00094 
Sluckin, W. (ed.). 1979. Fear in animals and man. New York: Van Nostrand Reinhold Co.

Smith, M.E. i M.A. Masson. (red.). 2000. The ancient civilizations of Mesoamerica: a reader. Oxford: Blackwell.

Steimer, T. 2002. "The biology of fear- and anxiety-related behaviors". Dialogues in Clinical Neuroscience 4.3. 231-249.

Tuan, Yi-Fu. 1979. Landscapes of fear. New York: Pantheon Books. Także Landscapes of fear. 2013. Minneapolis: University of Minnesota Press.

Whalen, P.J. i E.A. Phelps. (red.). 2009. The human amygdala. New York: The Guilford Press.

Wrangham, R. 2019. The goodness paradox: the strange relationship between virtue and violence in human evolution. New York: Pantheon Books.

Źrałka, J. 2008. W krainie czerni i czerwieni. Kultury prekolumbijskiej Mezoameryki. Warszawa: Wydawnictwa Uniwersytetu Warszawskiego. 